\title{
MORPHOLOGICAL AND HISTOLOGICAL VARIATIONS OF HUMAN PLACENTA IN HYPERTENSIVE DISORDERS OF PREGNANCY
}

\author{
Siva Sree Ranga. M.K ${ }^{* 1}$, Adaline Thangam. T.F ${ }^{2}$, M.C. Vasantha Mallika ${ }^{3}$, M.V. Indira ${ }^{4}$. \\ ${ }^{*}$ Assistant Professor, Anatomy, Dr.SM CSI Medical College, Karakonam, India. \\ 2 Professor, Obstetrics and Gynaecology, Dr.SM CSI Medical College, Karakonam, India. \\ ${ }^{3}$ Associate Professor, Community Medicine, Dr.SM CSI Medical College, Karakonam, India. \\ ${ }^{4}$ Professor, Anatomy, Dr.SM CSI Medical College, Karakonam, India.
}

\section{ABSTRACT}

Background: Hypertensive disorders of pregnancy form leading cause of maternal as well as foetal morbidity and mortality. Many disorders of pregnancy are associated with gross pathological changes in placenta, the feto-maternal organ which is vital for maintaining pregnancy and for promoting growth of the fetus.

Materials and Methods: A cross sectional study was conducted among placentae from thirty pregnant mothers with hypertension and thirty mothers with uncomplicated pregnancy in the Department of Obstetrics and Gynaecology, Dr.Somervell Memorial CSI Medical College, Karakonam. The gross morphological and histological examination of placentae was done.

Results: The placental weight, diameter and thickness were reduced in the hypertensive group. The hypertensive placentae showed more incidence of infarction, retroplacental haematoma and calcification. Histologically, hypertensive placentae showed large number of syncytial knots, cytotrophoblastic proliferation, fibrinoid necrosis and villus hyalinization. New born babies of hypertensive group had reduced birth weight and low Apgar score.

Conclusion: Hypertensive disorders of pregnancy show significant differences in various parameters of placental morphology and histology. Hypertensive disorders of pregnancy adversely influence the foetal outcome.

KEY WORDS: Placenta, Infarction, Retro placental haematoma, Calcification, foetal outcome.

Address for Correspondence: Dr. Siva Sree Ranga. M.K., Siva Sree Sadanam, Vellarada, Thiruvananthapuram Dist. Kerala, India. PIN 695 505; Mobile: 9447696069;

E-Mail: sivasreeranga@gmail.com

\section{Access this Article online}

Quick Response code

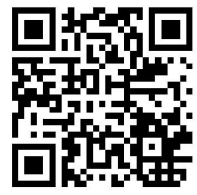

DOI: $10.16965 /$ ijar.2017.115
Web site: International Journal of Anatomy and Research ISSN 2321-4287

www.ijmhr.org/ijar.htm

Received: 17 Jan 2017

Accepted: 24 Feb 2017

Peer Review: 20 Jan 2017

Published (O): 31 Mar 2017

Revised: None

\section{INTRODUCTION}

The human placenta is an intrauterine fusion of fetal and maternal tissues for the purpose of physiological transfer of nutrients and oxygen from mother to fetus and transfer of waste products of metabolism from fetus to mother for continuation of fetal life. Placenta is the vital organ for maintaining pregnancy and promoting development of the fetus [1]. The intrauterine existence of fetus is dependent on this vital organ.

The hypertensivedisorders of pregnancy are responsible for $5-8 \%$ of all maternal deaths [2]. Hypertensive disorders of pregnancy are also 
strongly associated with foetal growth retardation and prematurity leading to perinatal morbidity and mortality.

Placenta has drawn attention as valuable indicator for foetal and maternal diseases [3]. Many disorders of pregnancy which are associated with high perinatal morbidity and mortality have shown gross pathological changes in placenta ${ }^{1}$. Many maternal diseases or disorders bring about changes in placenta at morphological and microscopic level. Abnormal placenta adversely affects the fetal outcome [4]. As placenta is the mirrorof maternal and foetal status, complications like hypertension in pregnancy has reflected in the placenta in a significant way both macroscopically and microscopically [5-8].

Though a wide variety of morphologic changes has been reported in the placentae of hypertensive pregnancies, the definitive pathogenesis of these structural abnormalities, their correlation with placental function and their relationship to fetal and maternal outcome have not been studied in rural areas of South Kerala, India.

This research work has been conducted at Dr. Somervell Memorial CSI Medical College, Karakonam, a health care facility in rural South Kerala, India with the objectives to study the morphological and histological variations of human placenta in hypertensive disorders of pregnancy and to compare the findings of the study with those of normal pregnancies and to correlate the morphologic changes of placenta in hypertensive disorders of pregnancy with possible complications in the new born.

\section{OBJECTIVES}

- To study the morphological and histological variations of human placenta in hypertensive disorders of pregnancy.

- To compare the findings of the study with those of human placentae of normal pregnancies.

- To correlate the morphologic changes of placenta in hypertensive disorders of pregnancy with possible complications in the new born.

\section{MATERIALS AND METHODS}

A cross sectional study was conducted among sixty pregnant ladies admitted in the labour room, Departmentof Obstetrics and Gynaecol- ogy, Dr.Somervell Memorial CSI Medical College, Karakonam, South Kerala, India during a period of six months from June 2016.

The study group comprised thirty placentae from pregnancies with hypertension. Those pregnant women who had blood pressure at or above $140 / 90 \mathrm{~mm}$ of $\mathrm{Hg}$ on at least two occasions six hours apart after twenty weeks of gestation, with or without oedema and/or proteinuria formed the hypertensive group. The controlgroup comprised thirty placentae from pregnant women with normal blood pressure, without proteinuria and without oedema.

Inclusion criteria: Pregnancy Induced Hypertension (Pre-eclampsia and Eclampsia), Gestational Hypertension.

Exclusion criteria: All other maternal conditions which lead to small placental size, placental infarcts and Intra-uterine Growth Retardation.

Before the study, approval from the Institutional Ethics Committee and permission from the Professor and Head of the Department of Anatomy and Professor and Head of Department of Obstetrics and Gynecology were obtained. Informed consent was taken from the parents of the newborns.

Method of Data Collection using pretested schedule: Clinical findings of mothers were collected from case sheets, along with recording of their obstetric and medical history. Their investigation reports were checked (blood sugar, urea, creatinine, haemoglobin levels, urine for albumin, pus cells and ophthalmic examinations). Mothers were considered to be hypertensive if the blood pressure was $140 / 90$ or above $\mathrm{mm}$ of $\mathrm{Hg}$.

All placentae were collected immediately after delivery in a clean tray. Placentae were washed in running tap water. Any abnormality of cord and membranes was noted. The placentae along with cord were coded. The membranes and cord at their attachment to the placenta were cut off by sharp scissors. The placentae were cleaned free of blood clots during washing and excess water was removed with blotting paper. Then placentae were immersed in $10 \%$ formalin.

Examination of placenta was done for gross and histological studies. 
Size, Shape, Surface Area and thickness of placentae, marginal veins for any thrombus, number of cotyledons, condition of membranes, presence of infarction, calcifications and site of insertion of umbilical cord were noted. The weightof the placenta was taken using standard weighing machine.

Tissues were taken from the following placental sites for histological studies:-

- Near the insertion of the umbilical cord

- Margins - 12, 3, 6, 9 o' clock positions

- Centre of the placenta

- Fibrotic area if any

- Infarcted area if any

- Umbilical cord at placental junction and cut end

Placental tissues were stained and examined under microscope for number of syncytial knots, cytotrophoblastic cellular proliferation, fibrinoid necrosis, endothelial proliferation, calcified and hyalinised villous spots in the hypertensive group in comparison to normotensive group.

The newborn babies were examined for congenital anomalies. Neonatal outcome in the form of birth weight, Apgar score, need for neonatal resuscitation and admission to Newborn Intensive Care Unit were noted. Feto-placental weight ratio was calculated in each case.

Statistical analysis was made using Student's T Test and Chi Square Test

\section{RESULTS AND DISCUSSION}

Among the study (hypertensive) group, maximum number of placentae were from the Preeclamptic mothers

Among the ladies attended the Department of Obstetrics and Gynaecology, Dr.Somervell Memorial CSI Medical College,Karakonam during the study period of six months from June 2016, thirty pregnant mothers presented with hypertension.

Table 1: Distribution of study (hypertensive) group.

\begin{tabular}{|c|c|c|}
\hline $\begin{array}{c}\text { Hypertensive disorders of } \\
\text { pregnancy }\end{array}$ & Number of cases & Percentage \\
\hline Gestational Hypertension & 12 & 40 \\
\hline Pre eclampsia & 17 & 56.7 \\
\hline Eclampsia & 1 & 3.3 \\
\hline Total & 30 & 100 \\
\hline
\end{tabular}

Int J Anat Res 2017, 5(1):3591-98. ISSN 2321-4287
The study group comprised placentae from thirty pregnancies with hypertension. The controlgroup comprised thirty placentae from pregnant mothers with normal blood pressure, without proteinuria and without edema.

Table 2: Distribution according to maternal age.

\begin{tabular}{|c|c|c|}
\hline $\begin{array}{c}\text { Age group } \\
\text { (years) }\end{array}$ & $\begin{array}{c}\text { Hypertensive } \\
\text { mothers }\end{array}$ & $\begin{array}{c}\text { Non hypertensive } \\
\text { mothers }\end{array}$ \\
\hline $20-24$ & 10 & 15 \\
\hline $25-29$ & 16 & 12 \\
\hline $30-34$ & 4 & 3 \\
\hline Total & 30 & $\mathbf{3 0}$ \\
\hline $\begin{array}{c}\text { Mean } \pm \text { std. } \\
\text { deviation }\end{array}$ & $25.6 \pm 3.8$ & $24.6 \pm 3.3$ \\
\hline "t" & \multicolumn{3}{|c|}{1.077} \\
\hline df & \multicolumn{3}{|c|}{$\mathbf{P}>0.05$} \\
\hline Significance & \multicolumn{3}{|c|}{} \\
\hline
\end{tabular}

The mean age of hypertensive mothers was 25.6 \pm 3.8 years

The mean age of non hypertensive mothers 24.6 \pm 3.3 years.

The two groups were not significantly different $(P>0.05)$.

Table 3: Distribution according to maternal parity.

\begin{tabular}{|c|c|c|c|c|c|c|}
\hline Parity & Hypertension & $\begin{array}{c}\text { Non } \\
\text { Hypertension }\end{array}$ & Total & $\chi^{2}$ & $\mathrm{df}$ & Significance \\
\hline Primi & 26 & 28 & 54 & \multirow{2}{*}{0.185} & \multirow{2}{*}{1} & \multirow{2}{*}{$\mathrm{P}>0.05$} \\
\hline Multi & 4 & 2 & 6 & & & \\
\hline Total & 30 & 30 & 60 & & & \\
\hline
\end{tabular}

There was no significant difference between the hypertensive and nonhypertensive groups in respect of maternal parity ( $P>0.05)$.

Table 4: Comparison of foetal outcome.

\begin{tabular}{|c|c|c|c|c|c|c|c|c|c|c|}
\hline \multirow{2}{*}{ Variable } & \multicolumn{3}{|c|}{ Hypertensive } & \multicolumn{3}{|c|}{ Non Hypertensive } & \multirow{2}{*}{$\begin{array}{l}\text { Difference } \\
\text { of means }\end{array}$} & \multirow{2}{*}{ ' $\mathrm{t}$ ' } & \multirow{2}{*}{$d f$} & \multirow{2}{*}{ Significance } \\
\hline & $n$ & Mean & SD & $n$ & Mean & SD & & & & \\
\hline Birth weight & 30 & 2.5 & 0.7 & 30 & 2.9 & 0.4 & 0.4 & 2.973 & 58 & $P<0.01$ \\
\hline Apgar score at birth & 28 & 6.9 & 1.8 & 30 & 9 & 0 & 2.1 & 6.294 & 56 & $P<0.001$ \\
\hline $\begin{array}{l}\text { Apgar score at } 5 \\
\text { minutes }\end{array}$ & 28 & 8.5 & 0.8 & 30 & 10 & 0 & 1.5 & 10.13 & 56 & $P<0.001$ \\
\hline
\end{tabular}

The mean birth weight of babies of hypertensive group was $2.5 \pm 0.7 \mathrm{~kg}$

The mean birth weight of babies ofnon hypertensive group was $2.9 \pm 0.4 \mathrm{~kg}$.

$50^{\text {th }}$ percentile value for babies of hypertensive group was 2.6

$50^{\text {th }}$ percentile value for babies of non hypertensive group was 2.845

In the present study, the birth weight of neonates was significantly low in the hyperten 
sivegroup $(\mathrm{P}<0.01)$.

UdainaA et al (2004) [1], Majumdar S et al (2005) [6], Rosana R.M. et al (2003) [7] and Abdul HafeezBalochetal (2012)[9] observed similar finding in the birth weight of neonates.

In the presentstudy, Apgar scores of new born babies was found to be significantly low in the hypertensive group $(\mathrm{P}<0.001)$.

The means of Apgar scores of babies at birth of hypertensive and nonhypertensive groups were $6.9 \pm 1.8$ and $9 \pm 0$ and the same at five minutes were $8.5 \pm 0.8$ and $10 \pm 0$ respectively. The finding was comparable with studies by Majumdar S.et al (2005) [6] and Duley L ( 2003) [10].

Table 5: Comparison of pregnancy outcome.

\begin{tabular}{|c|c|c|c|c|c|c|c|c|}
\hline \multirow{2}{*}{ SI. No } & \multirow{2}{*}{$\begin{array}{c}\text { Pregnancy } \\
\text { outcome }\end{array}$} & \multirow{2}{*}{ Component } & \multicolumn{2}{|c|}{$H T=30$} & \multicolumn{2}{|c|}{ Non $\mathrm{HT}=30$} & \multirow{2}{*}{ ' $z$ ' } & \multirow{2}{*}{ Significance } \\
\hline & & & No & $\%$ & No & $\%$ & & \\
\hline \multirow{2}{*}{1} & \multirow{2}{*}{ Mode of delivery } & Vaginal & 18 & 60 & 27 & 90 & \multirow{2}{*}{2.86} & \multirow{2}{*}{$P<0.01$} \\
\hline & & LSCS & 12 & 40 & 3 & 10 & & \\
\hline \multirow{2}{*}{2} & \multirow{2}{*}{ Term of baby } & Pre-term & 10 & 33.3 & 0 & 0 & \multirow{2}{*}{3.87} & \multirow{2}{*}{$P<0.001$} \\
\hline & & Term & 20 & 66.7 & 30 & 100 & & \\
\hline \multirow{2}{*}{3} & \multirow{2}{*}{ Type of birth } & Live & 28 & 93.3 & 30 & 100 & \multirow{2}{*}{1.468} & \multirow{2}{*}{$P>0.05$} \\
\hline & & IUD & 2 & 6.7 & 0 & 0 & & \\
\hline \multirow[t]{2}{*}{4} & \multirow[t]{2}{*}{ NICU admissions } & Yes & 9 & 30 & 0 & 0 & \multirow[t]{2}{*}{3.586} & \multirow[t]{2}{*}{$P<0.001$} \\
\hline & & No & 21 & 70 & 30 & 100 & & \\
\hline
\end{tabular}

HT- Hypertensive; Non HT- Non Hypertensive

$90 \%$ of nonhypertensive mothers delivered vaginally while $60 \%$ of hypertensive mothers delivered by caesarean section.

The difference between them was statistically highly significant $(P<0.01)$.

$30 \%$ of babies born to hypertensive mothers required admission and treatment in the Neonatal Intensive Care Unit. No baby of non hypertensive mothers was admitted in NICU. $\mathrm{P}<0.001$

Table 6: Gross morphology of placenta.

\begin{tabular}{|c|c|c|c|c|c|c|c|c|}
\hline \multirow{2}{*}{ SI.No } & \multirow{2}{*}{$\begin{array}{l}\text { Placental } \\
\text { features }\end{array}$} & \multirow{2}{*}{ Component } & \multicolumn{2}{|c|}{ HT } & \multicolumn{2}{|c|}{ Non HT } & \multirow{2}{*}{$' z^{\prime}$} & \multirow{2}{*}{ Significance } \\
\hline & & & No & $\%$ & No & $\%$ & & \\
\hline \multirow{2}{*}{1} & \multirow{2}{*}{ Shape } & Discoid & 22 & 73.3 & 30 & 100 & \multirow{2}{*}{5.894} & \multirow{2}{*}{$P<0.001$} \\
\hline & & Irregular & 8 & 26.7 & 0 & 0 & & \\
\hline \multirow{2}{*}{2} & \multirow{2}{*}{ Haemotoma } & Yes & 2 & 6.7 & 0 & 0 & \multirow{2}{*}{1.433} & \multirow{2}{*}{$P>0.05$} \\
\hline & & No & 28 & 93.3 & 30 & 100 & & \\
\hline \multirow{2}{*}{3} & \multirow{2}{*}{ Infarction } & Yes & 11 & 36.7 & 2 & 6.7 & \multirow{2}{*}{2.821} & \multirow{2}{*}{$P<0.01$} \\
\hline & & No & 19 & 63.3 & 28 & 93.3 & & \\
\hline \multirow{2}{*}{4} & \multirow{2}{*}{ Calcification } & Yes & 17 & 56.7 & 7 & 23.3 & \multirow{2}{*}{2.635} & \multirow{2}{*}{$P<0.01$} \\
\hline & & No & 13 & 43.3 & 23 & 76.7 & & \\
\hline
\end{tabular}

HT- Hypertensive; Non HT- Non Hypertensive Placentae of nonhypertensive group were discoid in shape. lirregular shape of placentae was observed among $26.7 \%$ of the hypertens- ives. Difference in shape between the two groups was statistically significant $(P<0.001)$.

UdainaAetal (2004) [5], MajumdarSetal (2005) [6] and RosanaR.M.etal (2003) [7].noted similar finding among hypertensives.

$6.7 \%$ of placentae of hypertensive group showed retroplacental haematoma. No haemotoma was present in the placentae of nonhypertensives. This gross morphological finding was found to be statistically not significant $(P>0.05)$ in the present study. Macpherson (1991) [11] reported a three fold increase in incidence of retroplacental hematoma among hypertensives. Study by Tangirala S, kumariD [3] found that gross lesions like retro placental hematomas were more in the hypertensive group which adversely influence the perinatal outcome.

The incidence of infarction among the hypertensive placentae was $36.7 \%$ in the present study and the same of the non hypertensives was $6.7 \%$. The observed difference between the two groups was statistically highly significant $(P<0.01)$.

Udaina et al (2004) [5], Majumdar S.et al (2005) [6] and Rosana R.M. et al (2003) [7]made similar observation in their study.

In the present study, presence of infarction was related to low birth weight and intra uterine death of foetus.

Incidence of calcification was $56.7 \%$ in the hypertensive group and $23.3 \%$ in the non hypertensives group. The difference of occurrence was statistically highly significant $(P<0.01)$.

Majumdar S etal (2005) [6] also observed more foci of calcification in the hypertensive group.

In the present study, intra uterine death and low foetal weight was noticed among cases with more placental calcification.

Table 7: Other placental mophological findings.

\begin{tabular}{|c|c|c|c|c|c|c|c|c|c|c|}
\hline \multirow{2}{*}{ Variable } & \multicolumn{3}{|c|}{ HT } & \multicolumn{3}{|c|}{ Non HT } & \multirow{2}{*}{$\begin{array}{l}\text { Difference } \\
\text { of means }\end{array}$} & \multirow{2}{*}{$\mathbf{I}^{\prime \prime}$} & \multirow{2}{*}{$d f$} & \multirow{2}{*}{ Significance } \\
\hline & $n$ & Mean & SD & $n$ & Mean & SD & & & & \\
\hline Placenta weight & 30 & 455.7 & 59.9 & 30 & 516.7 & 25.7 & 60.3 & 5.073 & 58 & $P<0.01$ \\
\hline Placenta diameter & 30 & 14.1 & 0.7 & 30 & 19.1 & 0.9 & 5 & 24.459 & 58 & $P<0.001$ \\
\hline Placenta thickness & 30 & 1.9 & 0.9 & 30 & 2.4 & 0.1 & 0.5 & 3.023 & 58 & $P<0.01$ \\
\hline Cotyledon & 30 & 16.1 & 2.5 & 30 & 19.1 & 1.2 & 3 & 6.08 & 58 & $P<0.001$ \\
\hline Foeto placental ratio & 30 & 5.5 & 1.9 & 30 & 5.6 & 0.7 & 0.1 & 0.193 & 58 & $P>0.05$ \\
\hline
\end{tabular}

HT- Hypertensive; Non HT- Non Hypertensive 
The mean placental weight of hypertensive group was $455.7 \pm 59.9$.

The mean placental weight of Non hypertensives was $516.7 \pm 25$.

The present study observed statistically significant reduction of placental weight $(P<0.01)$ in the hypertensive group.

UdainaAetal(2004) [5], MajumdarSetal (2005) [6], Rosana RM Correa et al (2008) [7], Kotgirwar Sheetaletal(2009) [12], VirupaxiRDetal (2011) [13] David J PBarkeretal (2010) [14], Abhilasha Dadhichetal (2012) [15], Pradeep S Londheetal (2011) [16] and Johan Eriksson [17] reported similar finding.

Mean placental diameter of hypertensive group was $14.1 \pm 0.7$

Mean placental diameter of Non hypertensive group was $19.1 \pm 0.9$.

$\mathrm{P}<0.001$ statistically very highly significant.

The mean placental thickness among the two groups were $1.9 \pm 0.9$ and $2.4 \pm 0.1$ and the difference was statistically highly significant $(P<0.01)$.

Both diameter and thickness of placenta were significantly reduced in the hypertensive group $(P<0.01)$ in the present study. Similar findings were observed by Abhilasha Dadhich et al (2012) [15] and PandureM.Metal (2011) [18].

The mean number of Cotyledons of hypertensive group was $16.1 \pm 2.5$ and that of non hypertensive group was $19.1 \pm 1.2$. The observed difference was statistically very highly significant $(P<0.001)$.

Abhilasha Dadhichetal (2012)[15] and MajumdarSetal (2005) [6] also observed less number of cotyledons in placentae of hypertensives.

Abdul HafeezBaloch (2012) [9] found that the number of cotyledons were almost same in hypertensive and non hypertensive groups.

The Foeto placental ratio of the two groups were $5.5 \pm 1.9$ and $5.6 \pm 0.7$ respectively. This finding was not statistically significant $(P>0.05)$.

Insertion of Placenta: Udaina et al (2004) [5] and Majumdar Setal (2005) [6] observed that marginal insertion of cord was significantly associated with hypertensive placentae.

In the hypertensive group of the present study, five placentae showed abnormal insertion of cord. Among them, four placentae showed marginal insertion (Fig.1) and one showed velamentous insertion while the placentae of normotensive group showed central insertion of umbilical cord.

There was insignificant association between insertion of umbilical cord and hypertension in pregnancy $(P>0.05)$ in this study.

Fig. 1: Placenta from hypertensive mother - maternal aspect.

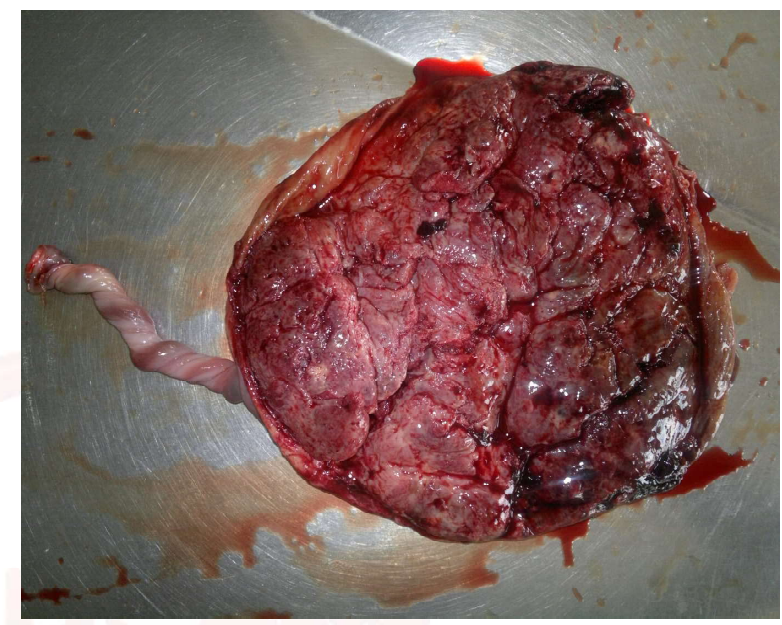

Fig. 2: Placenta from hypertensive mother - foetal aspect.

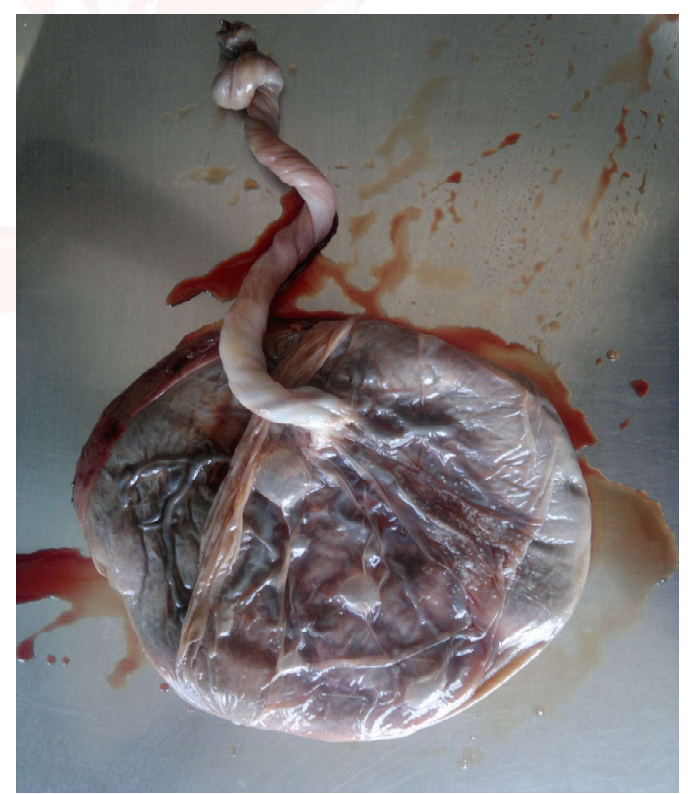

$63.3 \%$ of placentae from hypertensive mothers showed fibrinoid necrosis (Fig.6) and there was no incidence among the non hypertensive group. The difference showed very high statistical significance $(P<0.001)$.

Udainia et al (2004) [5] reported that fibrinoid necrosis,endothelial proliferation of arteries and hyalinization probably leads to placental insufficiency and ultimately to foetal growth retardation 
Table 8: Histological findings of placentae.

\begin{tabular}{|c|c|c|c|c|c|c|c|c|}
\hline \multirow{2}{*}{ SI.No } & \multirow{2}{*}{$\begin{array}{l}\text { Histological } \\
\text { findings of } \\
\text { placenta }\end{array}$} & \multirow{2}{*}{$\begin{array}{c}\text { Present/Ab } \\
\text { sent }\end{array}$} & \multicolumn{2}{|c|}{ HT } & \multicolumn{2}{|c|}{ Non HT } & \multirow{2}{*}{ 'Z' } & \multirow{2}{*}{ Significance } \\
\hline & & & No & $\%$ & No & $\%$ & & \\
\hline \multirow{2}{*}{1} & \multirow{2}{*}{ Syncytial knots } & Present & 19 & 63.3 & 7 & 23.3 & \multirow{2}{*}{3.126} & \multirow{2}{*}{$P<0.01$} \\
\hline & & Absent & 11 & 36.7 & 23 & 76.7 & & \\
\hline \multirow{2}{*}{2} & \multirow{2}{*}{$\begin{array}{c}\text { Cytotrophoblstic } \\
\text { proliferation }\end{array}$} & Present & 19 & 63.3 & 3 & 10 & \multirow{2}{*}{4.286} & \multirow{2}{*}{$P<0.001$} \\
\hline & & Absent & 11 & 36.7 & 27 & 90 & & \\
\hline \multirow{2}{*}{3} & \multirow{2}{*}{ Infarction } & Present & 11 & 36.7 & 2 & 6.7 & \multirow{2}{*}{2.821} & \multirow{2}{*}{$P<0.01$} \\
\hline & & Absent & 19 & 63.3 & 28 & 93.3 & & \\
\hline \multirow{2}{*}{4} & \multirow{2}{*}{ Calcification } & Present & 17 & 56.7 & 7 & 23.3 & \multirow{2}{*}{2.635} & \multirow{2}{*}{$P<0.01$} \\
\hline & & Absent & 13 & 43.3 & 23 & 76.7 & & \\
\hline \multirow{2}{*}{5} & \multirow{2}{*}{$\begin{array}{l}\text { Fibrinoid } \\
\text { necrosis }\end{array}$} & Present & 19 & 63.3 & 3 & 0 & \multirow{2}{*}{5.273} & \multirow{2}{*}{$P<0.001$} \\
\hline & & Absent & 11 & 36.7 & 27 & 100 & & \\
\hline \multirow{2}{*}{6} & \multirow{2}{*}{$\begin{array}{c}\text { Villous } \\
\text { hyalinisation }\end{array}$} & Present & 5 & 16.7 & 0 & 0 & \multirow{2}{*}{5.455} & \multirow{2}{*}{$P<0.001$} \\
\hline & & Absent & 25 & 83.3 & 30 & 100 & & \\
\hline
\end{tabular}

$63.3 \%$ placentae from hypertensive mothers showed large number of Syncytial knots (Fig.7) and the same of their counterpart in Nonhypertensive group was $23.3 \%$ (Fig. 3-5). The difference is statistically highly significant $(p<0.01)$.

In Hypertensive group 63.3\% placentae showed Cytotrophoblstic Proliferation (Fig.8), where as in Nonhypertensive group $10 \%$ placentae had cytotrophoblstic proliferation. Thedifference is statistically very highly significant $(P<0.001)$.

A study by Majumdar etal [6] showed histological findings like cytotrophoblastic cellular proliferation, syncytial knot formation and fibrin plaque formation in greater amount in hypertensive placentae. Babies of such mothers were mostly small for date.

Villus hyalinization (Fig.9) was observed among $16.7 \%$ placentae of hypertensive group where as none was observed among of placentae of normotensive group. This difference was statistically very highly significant $(P<0.001)$. A study done by Aparna $N$ et al (2011) [19] concluded that gross abnormalities and villous lesions were significant in placentae of normotensive patients.

The incidence of infarction among the hypertensive placentae was $36.7 \%$ and the same of the non hypertensives was $6.7 \%$. The observed difference between the two groups was statistically highly significant $(P<0.01)$.

The incidence of calcification (Fig10) of placentae was increased in the hypertensive group. It showed very high statistical significance $(P<0.01)$.

Histopathological study by Ahmed M et al(2013) [20] showed significant number of syncitial knots, areas of fibrinoid necrosis, hyalinization, calcification, and medial coat proliferation of medium sized blood vessels in hypertensive group.

Deepalaxmi Salmani et al (2014) [21] found structural changes such as significant number of syncytial knots, areas of fibrinoid necrosis, areas of medial coat proliferation of medium sized blood vessels, areas of calcification, and areas of hyalinization in hypertensive placentae. A significant increase in syncytial knot formation in placental villi indicates disturbance in the hormonal factors, which may lead toaltered morphometry of placenta resulting in Pregnancy induced hypertension in the mother and to low birth weight in the new born.

Fig 3: Placenta showing small sized villi. Arrow shows syncytial knots. $10 \mathrm{X} \mathrm{H \& E}$

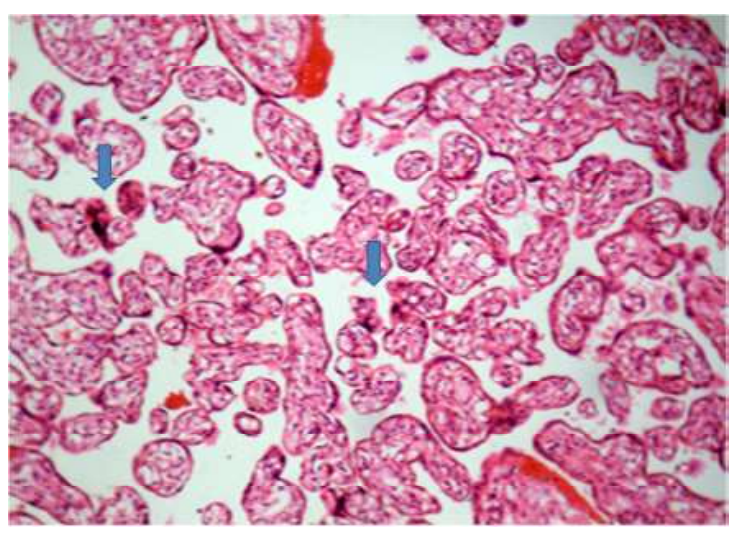


Fig. 4: Arrow shows stroma. $40 \mathrm{X}$ $H \& E$.

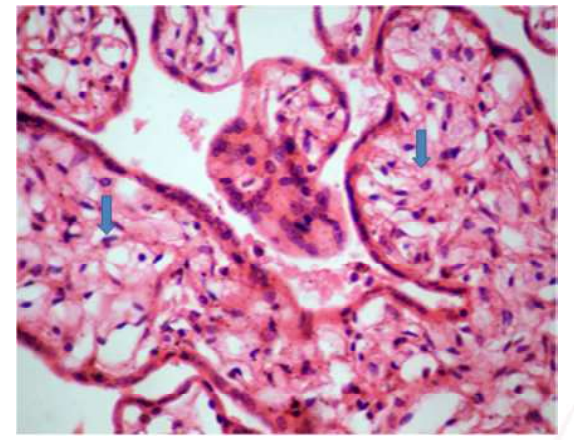

Fig. 7: Arrow shows syncytial knots 10 Fig 8: Arrow shows cytotrophoblastic $X H \& E$.

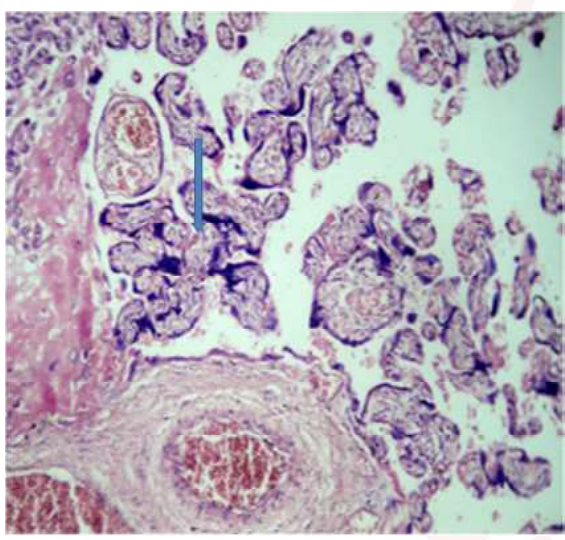
proliferation. $10 \times \mathrm{H} \& \mathrm{E}$.

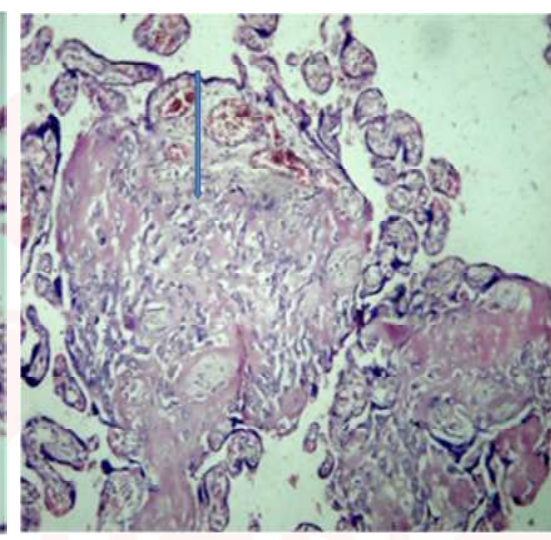

Fig. 6: Arrow showsfibrinoid necrosis of endothelium . $40 \mathrm{X} \mathrm{H \& E}$

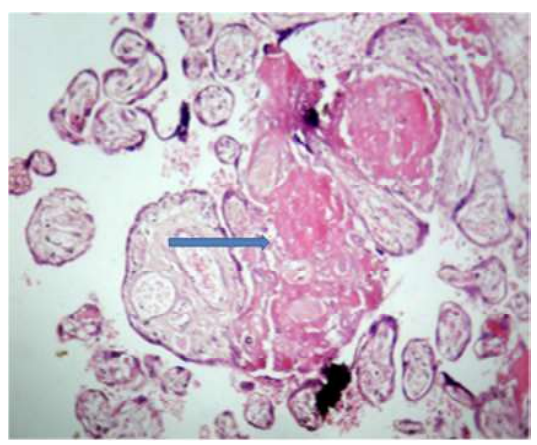

Fig 9: Arrow shows stromal hyalinization. $40 \mathrm{X} \mathrm{H \& E}$.
Fig. 10: Arrow shows calcification. $10 \times \mathrm{H} \& \mathrm{E}$.

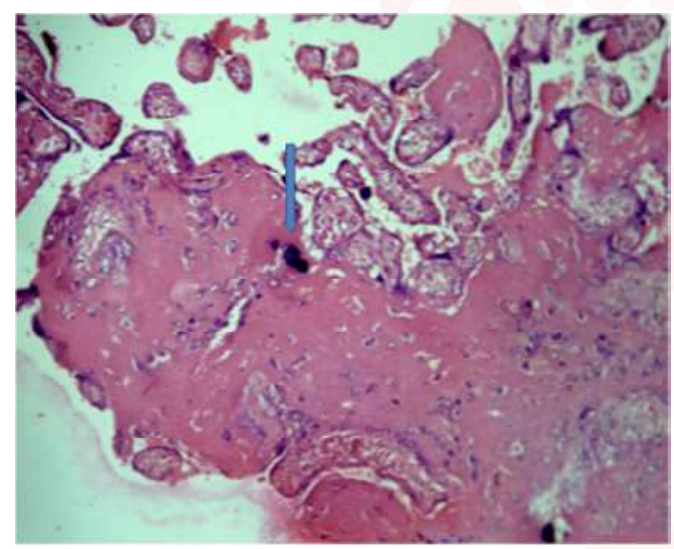

\section{CONCLUSION}

Present study has been planned to record the morphology and histology of placentae of hypertensive disorders of pregnancy and to compare the findings with those of placentae of normal pregnancy.

A group of thirty pregnant ladies with uncomplicated normal pregnancy and another group of thirty pregnant mothers with hypertension comparable in age and parity were selected from Department of Obstetrics and Gynaecology, Dr.SM CSI Medical College, Karakonam. The placentae were collected immediately after delivery from both the groups and morphological and histological findings were compared.
It may be concluded that hypertensive disorders of pregnancy show significant differences in various parameters of placental morphology and histology. Hypertensive disorders of pregnancy adversely influence foetal outcome. The placentae of mothers with hypertensive disorders of pregnancy show presence of retroplacental haematoma and infarction which may lead to placental insufficiency. This can lead to both foetal and maternal morbidity and mortality. Placenta has a great potential to provide valuable information in the case of an adverse foetal outcome.

Recommendations: Further studies may be required in different settings with larger sample size. More precise intervention strategies may be devised that can contribute to more effective management of the condition in the future. It will help to bring down the fetal and maternal mortality and morbidity.

\section{Conflicts of Interests: None}

\section{REFERENCES}

[1]. Udaina.A, Jain.M.L. Morphological Study of Placenta in Pregnancy Induced Hypertension with its Clinical Relevance.J.Anat.Soc.India,2001;50:24-27. 
[2]. Park K. Textbook of Preventive and SocialMedicine, 20th edn, BanarsidasBhanot Publishers, Jabalpur: Pg 482,2009.

[3]. Tangirala S, kumari D. Placental morphology in hypertensive disorders and its correlation to neonatal outcome. IAIM, 2015;2(11):35-38.

[4]. EskildA,Vatten LJ. Do pregnancies with PE have smallplacentas? A population study of 317688 pregnancieswith \& without growth restriction in the offspring.BJOG. 2010; 117:1521-1526.

[5]. Udaina.A, Bhagwat SS, Mehta CD, Relation between placental surface area, infarction and foetal distress in pregnancy induced hypertension with its clinical relevance. J AnatSoclnd 2004;53;1:27-30.

[6]. MajumdarS, Dasgupta H. A Study of Placenta In Normal And Hypertensive Pregnancies. . J AnatSoclnd 2005;54:1-9.

[7]. Rosana RM Correa, Daniel B. Gilio, Camila L. Cavellani, Marina C. Paschoini, Flávia A. Oliveira, Luís C. Peres, Marlene A. Reis, Vicente P. A. Teixeira and Eumenia C. C. Castro Placental morphometrical and histopathology changes in the different clinical presentations of Hypertensive Syndromes in Pregnancy. Arch Gynecolobstr 2008;277(1):201-206.

[8]. Kurdukar MD, Deshpande NM. Placenta in Pregnancy induced Hypertension. Indian J Pathol Mycrobiol 2007;50:493-497.

[9]. Abdul HafeezBaloch, Salma FarrukhMemon, Asmat Kamal Ansari.Comparison of Placentae from Hypertension Associated Pregnancies and Normal Pregnancies .JLUMHS January-April 2012;11(01).

[10]. Duley L. Preeclampsia and hypertensive disorders of pregnancy. Br Medl Bull 2003;67:161-176.

[11]. MacfersonTrevor.Fact and Fancy.ArchPathol Lab Med. 1991;115:672-679.

[12]. Kotgirwar Sheetal, Mohd Imtiaz, Gupta Vanita, Trivedi Soumitra.Morphology of placenta in pregnancy induced hypertension and its foetal outcome .Journal of Advance Researches in Biological Sciences,2009;1(2):109-114.
[13]. Virupaxi RD, Potturi BR, Shirol VS, Desai SP, Hukkeri VB. Morphology of placenta and its relation with small for date babies in 950 live births. Rec Res SciTechnol 2011;3:123-6.

[14]. David J.P. Barker, Kent L. Thornburg, Clive Osmond, EeroKajantie, Johan G. Eriksson.The surface area of the placenta and hypertensioninth e offspring in later life.Int. J. Dev. Biol. 2010;54:525-530.

[15]. AbhilashaDadhich ,SushmaK.Kataria, Kushal R. Kataria, PushpaPotaliya. Study of effect of eclampsia and chronic hypertension on gross morphology of placenta. Int J Biol Med Res. 2012;3(2):1771-1773.

[16]. Pradeep S Londhe, Abhay B Mane. Morphometric study of placenta and its correlation in normal and hypertensive pregnancies. International Journal of Pharma and Bio Sciences:Oct-Dec 2011;2(4):9756299.

[17]. Johan Eriksson, Tom Forsen, JaakoTuomilehto, Clive Osmond, David Barker. Fetal \&Chid hood growth andhypertension in adult life. Hypertension. 2000;36:790-794.

[18]. Pandure M.M.,Ghosh D.K morphology of preterm placenta and it's clinicopathological corelation Pravara Med Rev 2011;6(2).

[19]. AparnaNarasimha, Vasudeva DS. Spectrum of changes in placenta in toxaemia of pregnancy. Indian Journal of Pathology and Microbiology March 2011;54(1):15-20.

[20]. Maimoona Ahmed, Rekha G. Daver. Study of placental changes in pregnancy induced hypertension Int J Reprod Contracept Obstet Gynecol. 2013 Dec;2(4):524-527.

[21]. Deepalaxmi Salmani et al. Study of structural changes in placenta in pregnancy-induced hypertension, Nat SciBiol Med. 2014 ;5(2): 352-355.

How to cite this article:

Siva Sree Ranga. M.K, Adaline Thangam. T.F, M.C. Vasantha

Mallika, M.V. Indira. MORPHOLOGICAL AND HISTOLOGICAL

VARIATIONS OF HUMAN PLACENTA IN HYPERTENSIVE DISORDERS

OF PREGNANCY. Int J Anat Res 2017;5(1):3591-3598. DOI: 10.16965/ijar.2017.115 